\title{
Chemical Heat Storage Using an SiC Honeycomb Packed with $\mathrm{CaCl}_{2}$ Powder
}

\author{
Atsuhiro Ichinose, Kazuki Kuwata, Takehiro Esaki, Takayuki Matsuda, Noriyuki Kobayashi* \\ Nagoya University, Furo-cho, Chikusa-ku, Nagoya, Aichi, Japan \\ Email: *kobayashi@energy.gr.jp
}

How to cite this paper: Ichinose, A., $\mathrm{Ku}$ wata, K., Esaki, T., Matsuda, T. and Kobayashi, N. (2020) Chemical Heat Storage Using an $\mathrm{SiC}$ Honeycomb Packed with $\mathrm{CaCl}_{2}$ Powder. Journal of Materials Science and Chemical Engineering, 8, 23-32. https://doi.org/10.4236/msce.2020.811002

Received: May 23, 2020

Accepted: November 14, 2020

Published: November 17, 2020

Copyright $\odot 2020$ by author(s) and Scientific Research Publishing Inc. This work is licensed under the Creative Commons Attribution International License (CC BY 4.0).

http://creativecommons.org/licenses/by/4.0/

\begin{abstract}
Chemical heat storage is a promising technology for improving thermal energy efficiency. In this study, $\mathrm{CaCl}_{2}$ and $\mathrm{H}_{2} \mathrm{O}$ were selected as a reaction system for utilization of low-grade exhaust heat that is cooler than $200^{\circ} \mathrm{C}$. Heat discharging and charging were conducted through the $\mathrm{CaCl}_{2}$ hydration reaction. A silicon carbide honeycomb was adopted to improve heat transfer in the $\mathrm{CaCl}_{2}$ packed bed. The heat storage, condenser, and evaporator temperature were set at $150^{\circ} \mathrm{C}, 30^{\circ} \mathrm{C}$ and $90^{\circ} \mathrm{C}$ respectively. Repeated trials and experiments are time consuming for optimizing design of the equipment. Therefore, in this research, we constructed a simulation that can predict the performance of the device. A numerical simulation model was utilized in preparation for the design of the heat storage module. The consistency of both the simulation and the experimental results was confirmed by comparing them.
\end{abstract}

\section{Keywords}

Chemical Heat Storage, $\mathrm{CaCl}_{2}$, Heat Discharging, Simulation

\section{Introduction}

The development of technologies and systems for improving the energy efficiency and preventing global warming has received increasing attention in recent years. Improving thermal energy efficiency is vital for mitigating carbon dioxide emissions. A large amount of thermal energy is used in industrial processes, which is accompanied by a large amount of exhaust heat. Therefore, it is necessary to store and reuse exhaust heat [1] [2].

Chemical heat storage is among the promising heat management technologies for reducing exhaust heat and fuel consumption [3] [4] [5]. In this study, we focused on chemical heat storage, which has a high heat storage density. Chemical 
heat storage systems that use a gas-solid reaction offer a higher thermal storage capacity and a wider temperature application than absorption-based heat management systems [3]. The $\mathrm{CaCl}_{2} / \mathrm{H}_{2} \mathrm{O}$ reaction system was adopted, which involves a reversible chemical endothermic or exothermic reaction, as follows. The material used in this system is environmentally sustainable, commonly used, readily available, nontoxic, and chemically stable [6], and the working temperature is below $200^{\circ} \mathrm{C}$. Moreover, the $\mathrm{CaCl}_{2} / \mathrm{H}_{2} \mathrm{O}$ reaction system has already been studied for chemical heat storage, and the potential use of both sides of the reversible $\mathrm{CaCl}_{2} / \mathrm{H}_{2} \mathrm{O}$ reaction has been demonstrated in previous studies [6].

$$
\mathrm{CaCl}_{2}+2 \mathrm{H}_{2} \mathrm{O}(\mathrm{g}) \Leftrightarrow \mathrm{CaCl}_{2} \cdot 2 \mathrm{H}_{2} \mathrm{O}(\mathrm{s})+125.1 \mathrm{~kJ} / \mathrm{mol}
$$

The requirements for chemical heat storage by a packed bed-type reactor include a high heat output density, and the heat transfer rate of the packed bed is a key issue when enhancing this factor. We examined heat release and storage using a corrugated aluminum fin module, as aluminum has high thermal conductivity. However, there is the possibility of corrosion when using aluminum for chemical heat storage materials [7]. In this study, we selected silicon carbide $(\mathrm{SiC})$ as a heat exchanger module, as it is a promising material for increasing corrosion resistance. In addition, $\mathrm{SiC}$ has excellent characteristics, including its low density and high specific thermal conductivity. It is well known that $\mathrm{SiC}$ has excellent thermal stability and corrosion resistance [8] [9] [10]. We evaluated heat release and storage using a module containing a honeycomb structure composed of SiC.

\section{Experimental}

\subsection{Matelial}

Reagent anhydrous $\mathrm{CaCl}_{2}$ particles ( $>95 \%$ purity) were obtained from Wako Chemicals (Japan). The material was dried in an electric furnace at $180^{\circ} \mathrm{C}$ for 24 hours. The $\mathrm{CaCl}_{2}$ powder was unified by diameter $\left(d_{p}=125-250 \mu \mathrm{m}\right)$.

\subsection{Experimental Apparatus}

A schematic of the experimental setup for heat storage and release by the $\mathrm{CaCl}_{2} / \mathrm{H}_{2} \mathrm{O}$ reaction is shown in Figure 1. The equipment included a reactor, an evaporator, and a condenser, and the system alternates heat release and storage by changing the state of the control valve. During heat release, the valve between the reactor and evaporator was opened and a stream was supplied to a reactor. Each of these components was connected by vapor flow tubes. The components and vapor flow tubes were covered with glass wool and a combination of glass wool and electric heaters, respectively, to prevent condensation or heat loss. Each component was also connected to a thermostat bath as a heat source. The heat medium fluids supplied from the thermostat bath were circulated through the components. During heat storage, the valve between the reactor and condenser was opened and the stream was collected from a reactor. The reactor containing a $\mathrm{SiC}$ honeycomb structure is presented in detail in Figure 2. The 


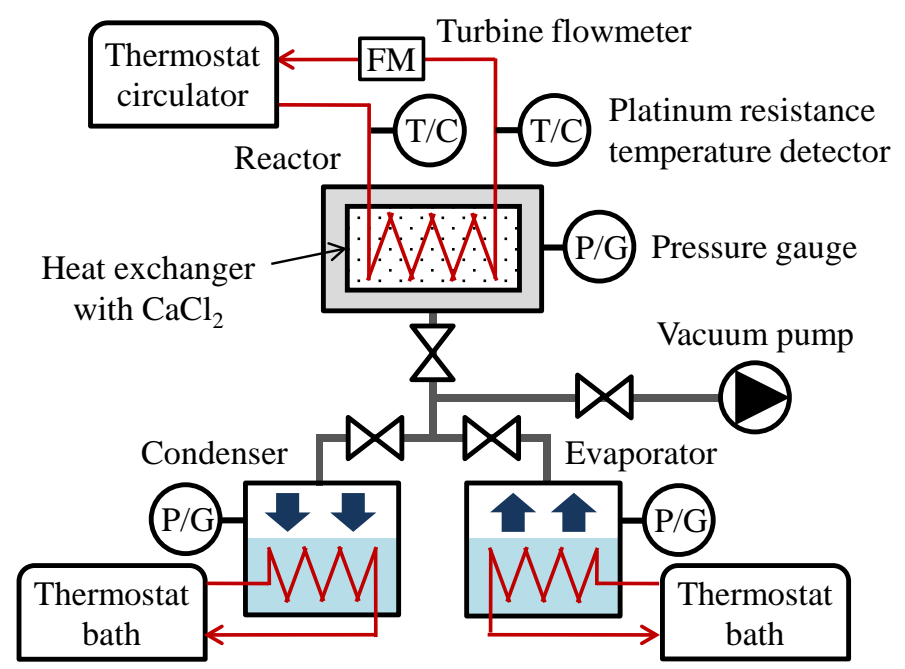

Figure 1. Experimental apparatus.

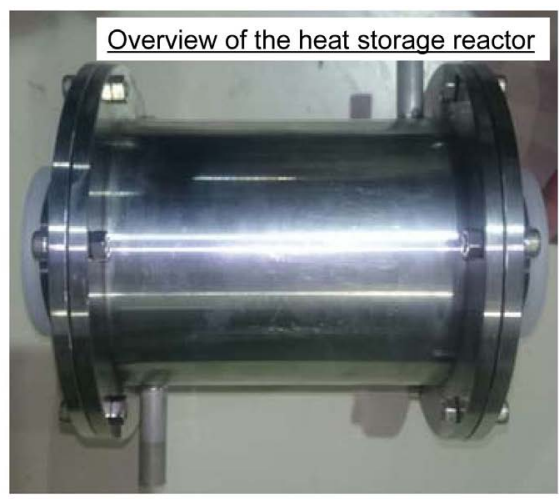

(A)
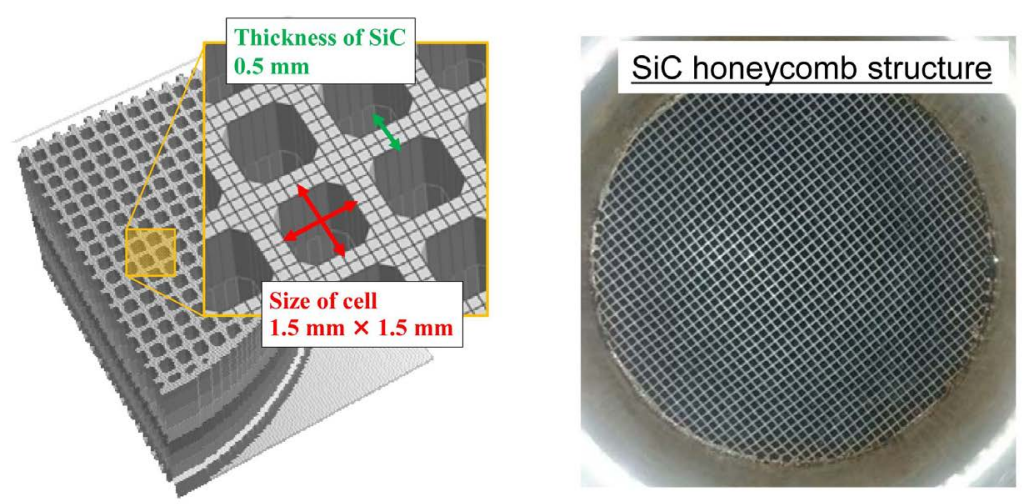

( B )

Figure 2. (A) Photograph of the heat storage reactor with honeycomb structure. (B) Overview of honeycomb structure.

size of the cell was $1.5 \times 1.5 \mathrm{~mm}$, and the $\mathrm{SiC}$ wall thickness was $0.5 \mathrm{~mm}$. The $\mathrm{SiC}$ acted as the heat transfer enhancement body of the filling layer. In addition, $\mathrm{CaCl}_{2}$ was used to fill the open spaces in the honeycomb's structure. The heat exchange fluid was fed around the core, and the heat storage module was filled with $84 \mathrm{~g}$ of the anhydrous $\mathrm{CaCl}_{2}$ particles. Its top and bottom were covered with 
nickel mesh before it was installed in the reactor chamber. The filling fraction based on the filling space was 0.38 . As a final step before initiating the experiments, the air was removed from the three components and vapor flow tubes by a vacuum pump. We measured the inlet and outlet temperature and flow rate of the heat exchange fluid that circulated through the reactor.

In the following experiments, the evaluation parameters were calculated based on the experimental results of the heat medium fluid's temperature and flow rate in the reactor. The fluid temperatures at the inlet and outlet of the heat storage module were measured using platinum resistance temperature detectors, and the fluid flow volume was measured using a turbine flow meter from Japan Flow Controls Co. Ltd. (Japan). Thermal H350, obtained from JULABO (Germany), was used as the heat medium fluid in the reactor. Water was used in the evaporator and condenser. The evaluation parameters included average volumetric power density, $Q_{\text {cum }}$,

$$
Q_{\text {cum }}=\frac{\int_{0}^{t} C_{p, f} \cdot \rho_{f} \cdot F \cdot \Delta T}{V_{\text {module }}}
$$

and the reaction conditions were selected carefully because hysteresis effects have been reported in previous studies. As indicated in Figure 3, the heat charging/discharging operation followed the chemically defined reaction lines for the hydration and dehydration of $\mathrm{CaCl}_{2}$, as well as the experimental conditions (the vapor pressure was controlled by the evaporator or condenser and the inlet temperature of the heat medium fluid tempering the reactor) applied in this study (charging/discharging conditions are denoted by white/black circles, respectively). During discharging, the water vapor was transported from the evaporator to the reactor, subsequently undergoing the exothermic reaction. During charging, the endothermic reaction thermally charged the reactor and the released water vapor was transported to the condenser. The operations were switched between using the control valves on the vapor flow tubes. The flow rate of the

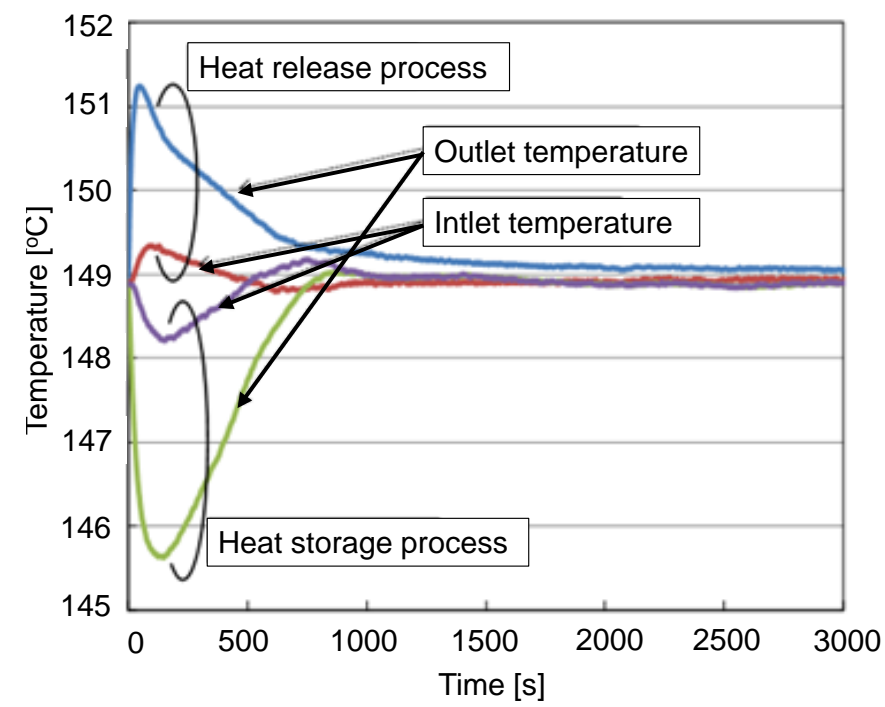

Figure 3. Temporal change in inlet and outlet temperature of heat exchange fluid. 
heat medium fluid in the reactor was $2 \mathrm{~L} / \mathrm{min}$ for both operations. The reaction, condenser, and evaporator temperatures were set at $150^{\circ} \mathrm{C}, 30^{\circ} \mathrm{C}$, and $90^{\circ} \mathrm{C}$, respectively. In the heat storage process, water vapor dehydrated from $\mathrm{CaCl}_{2}$ is recovered by the condenser. During the heat release process, water vapor generated from the evaporator undergoes a hydration reaction with $\mathrm{CaCl}_{2}$. The experimental conditions are outlined in Table 1.

\section{Result of Heat Release and Storage Behavior and Discussion}

The temporal changes in the temperature of the heat exchange fluid in the SiC honeycomb type reactor are shown in Figure 3. During heat release, the outlet temperature of heat exchange fluid was higher than the inlet temperature. However, during heat storage, the outlet temperature of the heat exchange fluid was lower than the inlet temperature. To compare the $\mathrm{SiC}$ honeycomb- and aluminum corrugated fin-type reactors [6]. The heat output and conversion ratio is shown in Figure 4. The maximum average heat output of the $\mathrm{SiC}$ honeycomb-type reactor was approximately $0.4-0.5$ times lower than that of corrugated aluminum fin type reactor. The hydration rate within 700 seconds after the start of heat release is similar, and the difference in the hydration rate increases

Table 1. Experimental conditions for heat storage and heat discharging process.

\begin{tabular}{rccc} 
& Reactor & Evaporator & Condenser \\
\hline Heat storage & $150^{\circ} \mathrm{C}$ & $90^{\circ} \mathrm{C}$ & \\
Heat storage & & & $30^{\circ} \mathrm{C}$ \\
\hline
\end{tabular}

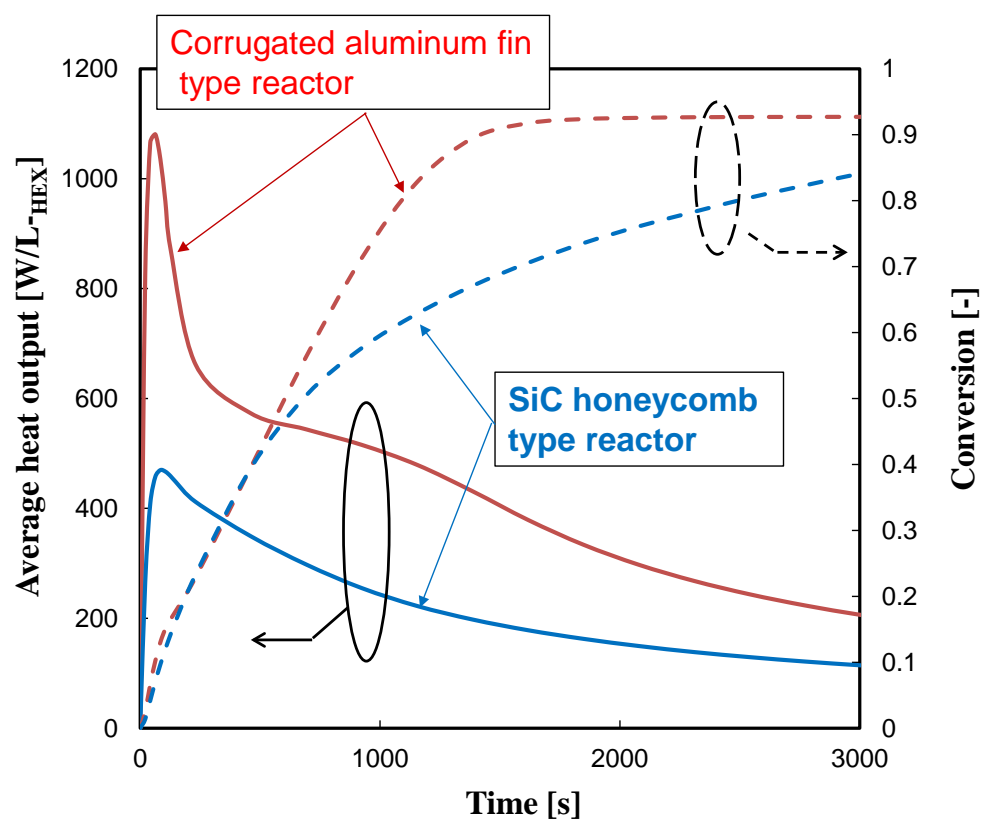

Figure 4. Comparison of heat release per volume between corrugated aluminum fin type and $\mathrm{SiC}$ honeycomb type reactor. 
as the time progresses. This is thought to be due to the thermal resistance between the heat exchange fluid and the packed bed. The time required for the reaction rate to reach $80 \%$ was approximately 2.8 times longer than that of the aluminum fin reactor. It is necessary to optimize the structure of packed bed and heat exchange flow path to upgrade the heat output performance.

\section{Simulation Model}

The results show that the heat release performance is affected by the structure of the heat exchanger. To practically use the chemical heat storage device, the structure of the reactor needs to be optimized. It is necessary to predict how the heat release performance changes when the structure of the reactor is changed, and the influence factor of the heat radiation performance should be extracted. The three-dimensional cylinder model with a honeycomb structure shown in Figure 5 was constructed. The calculation used the following equations for mass transfer, heat movement, and chemical reaction rate. The height of the cylindrical packed bed is $(Z)$, which is the thickness of the packed bed and the length of the flow path. The heat transfer of the contact surface between $\mathrm{CaCl}_{2}$ and $\mathrm{SiC}$ is calculated using the coefficient of overall heat transfer $\left(h_{c}\right)$. The equilibrium lines of the $0.3,1$, and 2 hydration states during the heat release step are shown in Table 2. The reaction lines for the hydration and dehydration were reported [11] [12] [13]. During the heat discharging process, hydration of the anhydrous $\mathrm{CaCl}_{2}$ occurs. There is a distribution in the hydration rate in the packed bed. This is because there is a distribution of temperature and water vapor pressure in the packed bed. The equilibrium line used for calculation is changed according to the hydration rate. The physical property values shown in Table 3 were obtained from the experiment.

Table 2. Relationship between vapor pressure and temperature for each $\mathrm{CaCl}_{2}$ hydration state.

\begin{tabular}{cc}
\hline Hydration state & Equilibrium pressure, $P[\mathrm{~Pa}]$ \\
\hline $0 \Leftrightarrow 0.3$ & $P=\exp (-69304.7 / R / T+148.85 / R)$ \\
$0.3 \Leftrightarrow 1$ & $P=\exp (-59519.5 / R / T+132.69 / R)$ \\
$1 \Leftrightarrow 2$ & $P=\exp (-47460.5 / R / T+106.42 / R)$ \\
\hline
\end{tabular}

Table 3. Simulation conditions.

\begin{tabular}{cccc}
\hline & SiC & $\mathrm{CaCl}_{2}$ & SUS \\
\hline Density, $\rho\left[\mathrm{kg} / \mathrm{m}^{3}\right]$ & 3000 & 817 & 8000 \\
Specific heat, $c[\mathrm{~J} / \mathrm{kg} / \mathrm{K}]$ & 667 & 903 & 625 \\
Thermal conductivity, $\lambda[\mathrm{W} / \mathrm{m} / \mathrm{K}]$ & 150 & 0.13 & 20 \\
coefficient of overall heat transfer & & 170 \\
between $\mathrm{CaCl}_{2}$ and $\mathrm{SiC}, h_{c}\left[\mathrm{~W} / \mathrm{m}^{2} / \mathrm{K}\right]$ & \multicolumn{3}{c}{ Heat exchange fluid } \\
\hline Density, $\rho\left[\mathrm{kg} / \mathrm{m}^{3}\right]$ & \multicolumn{3}{c}{951} \\
Specific heat, $c[\mathrm{~J} / \mathrm{kg} / \mathrm{K}]$ & \multicolumn{3}{c}{2033} \\
Convective heat transfer coefficient, $h_{l}\left[\mathrm{~W} / \mathrm{m}^{2} / \mathrm{K}\right]$ & 210 \\
\hline
\end{tabular}




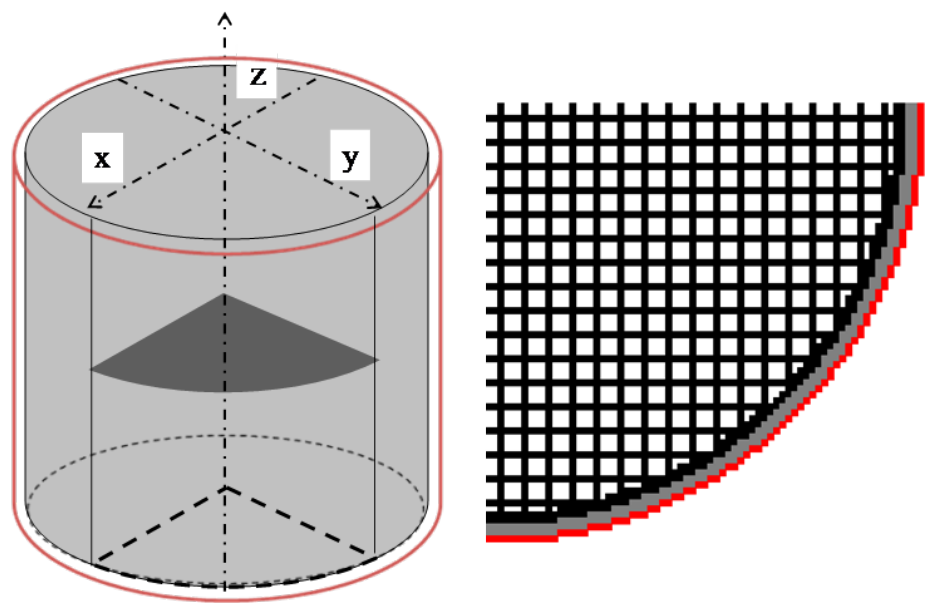

Figure 5. Three-dimensional cylindrical model with a honeycomb structure.

Mass balance of the packed bed

$$
\frac{\partial P}{\partial t}=D\left(\frac{\partial^{2} P}{\partial x^{2}}+\frac{\partial^{2} P}{\partial y^{2}}+\frac{\partial^{2} P}{\partial z^{2}}\right)-\frac{\rho_{M} R T}{\varepsilon} \frac{\partial X}{\partial t}
$$

Heat balance of the packed bed

$$
\frac{\partial T}{\partial t}=\frac{\lambda_{b}}{\rho_{M} C_{p M}}\left(\frac{\partial^{2} T}{\partial x^{2}}+\frac{\partial^{2} T}{\partial y^{2}}+\frac{\partial^{2} T}{\partial z^{2}}\right)-\frac{\rho_{M} \Delta H}{\rho_{M} C_{p M}} \frac{\partial X}{\partial t}
$$

Chemical reaction rate

$$
\begin{array}{ll}
k=a & \text { at } T<T_{e q} \\
k=0 & \text { at } T>T_{e q}
\end{array}
$$

Heat balance of the heat exchange fluid

$$
\frac{\partial T}{\partial t}=-\frac{\partial T}{\partial Z}
$$

Boundary condition

$$
\begin{gathered}
P=P_{\text {eva }} \quad \text { at } z=0 \text { or } z=Z \\
\frac{\partial P}{\partial z}=0 \quad \text { at } z=0 \text { or } z=Z \\
\lambda_{b} \frac{\partial T_{b}}{\partial x}=\frac{\partial T}{1 / h_{c}}=\lambda_{\text {sic }} \frac{\partial T_{\text {sic }}}{\partial x} \quad \text { at } x=x_{\text {sic }, 0} \\
\lambda_{b} \frac{\partial T_{b}}{\partial y}=\frac{\partial T}{1 / h_{c}}=\lambda_{\text {sic }} \frac{\partial T_{\text {sic }}}{\partial y} \quad \text { at } y=y_{\text {sic }, 0} \\
\lambda_{\text {sic }} \frac{\partial T_{\text {sus }}}{\partial r}=\frac{\partial T}{1 / h_{l}} \quad \text { at } r=r_{l}, r=\sqrt{x^{2}+y^{2}}
\end{gathered}
$$

\section{Result of the Heat Release Simulation and Experiment}

The temporal changes in the inlet and outlet temperature difference of the heat exchange fluid are shown in Figure 6. Under each condition, the highest difference 


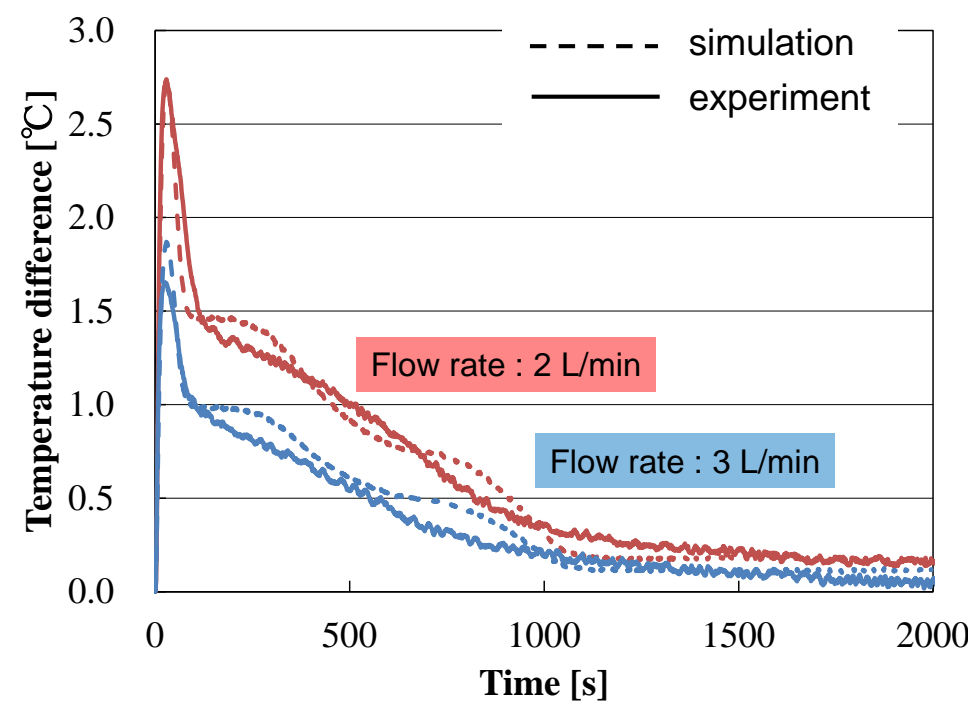

Figure 6. Temporal changes in the inlet and outlet temperature difference of the heat exchange.

in temperature appeared at approximately $50 \mathrm{~s}$, and it decreased smoothly after $100 \mathrm{~s}$. It is thought that the 0.3 and 1 hydration conditions were processed until reaching a calcium chloride hydration condition of 2 . Comparing the results of the simulation and the experiment confirmed that they were consistent. It has been demonstrated that this method of analysis could be used to design the heat storage module.

\section{Conclusion}

A $\mathrm{CaCl}_{2} / \mathrm{H}_{2} \mathrm{O}$ reaction system was adopted as a heat storage material, and could store heat at temperatures lower than $200^{\circ} \mathrm{C}$. The heat release and storage performance of the $\mathrm{CaCl}_{2}$ hydration reaction were examined. We presented the heat release and storage abilities of a reactor with an $\mathrm{SiC}$ honeycomb structure. The maximum average heat output of the $\mathrm{SiC}$ honeycomb-type reactor was approximately $0.4-0.5$ times lower than that of the corrugated aluminum fin-type reactor. The time required for reaching a reaction rate of $80 \%$ was approximately 2.8 times longer than that of the aluminum reactor. Optimizing the structure of the packed bed and the heat exchange flow path is necessary to upgrade the heat output performance. Repeated trials and experiments are time consuming for optimizing design of the equipment. Therefore, in this research, we constructed a simulation that can predict the performance of the device. Analysis model that simulates heat discharging was created. The validity of the analysis result was determined by comparing it with the experimental result. It was demonstrated that this analysis method could be applied to design a heat storage module.

\section{Acknowledgements}

This research is supported by "Knowledge Hub Aichi", Priority Reserch Project from Aichi Prefectural Government, Japan. We also would like to thank Editage 
(https://WWW.editage.jp/) for English language editing.

\section{Conflicts of Interest}

The authors declare no conflicts of interest regarding the publication of this paper.

\section{References}

[1] Cabonell, D., philippen, D., Haller, M.Y. and Frank, E. (2015) Modeling of an Ice Storage Based on a De-Icing Concept for Solar Heating Applications. Solar Energy, 121, 2-16. https://doi.org/10.1016/j.solener.2015.06.051

[2] Kortil, A.I.N. and Tlemsani, F.Z. () Experimental Investigation of Latent Heat Storage in a Coil in PCM Storage Unit. Journal of Energy Storage, 5, 177-186. https://doi.org/10.1016/j.est.2015.12.010

[3] Malik, A.S., Boyko, O., Atkar, N. and Young, W.F. (2001) A Comparative Study of MR Imaging Profile of Titanium Pedicle Screws. Acta Radiologica, 42, 291-293. https://doi.org/10.1080/028418501127346846

[4] Hu, T. and Desai, J.P. (2004) Soft-Tissue Material Properties under Large Deformation: Strain Rate Effect. Proceedings of the 26th Annual International Conference of the IEEE EMBS, San Francisco, 1-5 September 2004, 2758-2761.

https://doi.org/10.1109/IEMBS.2004.1403789

[5] Ortega, R., Loria, A. and Kelly, R. (1995) A Semiglobally Stable Output Feedback PI2D Regulator for Robot Manipulators. IEEE Transactions on Automatic Control, 40, 1432-1436. https://doi.org/10.1109/9.402235

[6] Kuwata, K., Esaki, T., Yasuda, M., Matsuda, T., Kobayashi, N. and Shiren, Y. (2017) Durability of Thermochemical Heat Storage Demonstrated through Long-Term Repetitive $\mathrm{CaCl}_{2} / \mathrm{H}_{2} \mathrm{O}$ Reversible Reactions. Journal of Renewable and Sustainable Energy, 9, 024102. https://doi.org/10.1063/1.4978351

[7] Ren, S.J., Charles, J., Wang, X.C., Nie, F.X., Romero, C., Neti, S., Zheng, Y., Hoenig, S., Chen, C., Cao, F., Bonner, R. and Pearlman, H. (2017) Corrosion Testing of Metals in Contact with Calcium Chloride Hexahydrate Used for Thermal Energy Storage. Material and Corrosion, 68, 1046-1056.

https://doi.org/10.1002/maco.201709432

[8] Chen, D., Sixta, M.E., Zhang, X.F., De Jounghe, L.C. and Ritchie, R.O. (2000) Role of the Grain-Boundary Phase on the Elevated-Temperature Strength, Toughness, Fatigue and Creep Resistance of Silicon Carbide Sintered with Al, B and C. Acta Materialia, 48, 4599. https://doi.org/10.1016/S1359-6454(00)00246-9

[9] van Dijen, F.K. and Mayer, E. (1996) Liquid Phase Sintering of Silicon Carbide. Journal of the European Ceramic Society, 16, 413.

https://doi.org/10.1016/0955-2219(95)00129-8

[10] Lee, S.K., Ishida, W., Lee, S.Y., Nam, K.W. and Ando, K. (2005) Crack-Healing Behavior and Resultant Strength Properties of Silicon Carbide Ceramic. Journal of the European Ceramic Society, 25, 569. https://doi.org/10.1016/j.jeurceramsoc.2004.01.021

[11] Molenda, M., Stengler, J., Linder, M. and Wörner, A. (2013) Reversible Hydration Behavior of $\mathrm{CaCl}_{2}$ at $\mathrm{High} \mathrm{H}_{2} \mathrm{O}$ Partial Pressures for Thermochemical Energy Storage. Thermochimica Acta, 560, 76-81. https://doi.org/10.1016/j.tca.2013.03.020

[12] Molenda, M., Stengler, J. and Linder, M. (2016) Heat Transformation Based on $\mathrm{CaCl}_{2} / \mathrm{H}_{2} \mathrm{O}$ Part A: Closed Operation Principle. Applied Thermal Engineering, 102, 
615-621. https://doi.org/10.1016/j.applthermaleng.2016.03.076

[13] Bouché, M., Richter, M. and Linder, M. (2016) Heat Transformation Based on $\mathrm{CaCl}_{2} / \mathrm{H}_{2} \mathrm{O}$ Part B: Open Operation Principle. Applied Thermal Engineering, 102, 641-647. https://doi.org/10.1016/j.applthermaleng.2016.03.102

\section{Nomenclature}

\begin{tabular}{|c|c|c|c|}
\hline $\mathrm{h}$ & : & \multicolumn{2}{|c|}{ Heat amount based value } \\
\hline theo & $:$ & \multicolumn{2}{|l|}{ Theory } \\
\hline $\mathrm{b}$ & $:$ & \multicolumn{2}{|c|}{ Reactant packed bed } \\
\hline eva & $:$ & \multicolumn{2}{|l|}{ Evaporator } \\
\hline c & $:$ & \multicolumn{2}{|c|}{ Contact surface with $\mathrm{CaCl}_{2}$ and $\mathrm{SiC}$} \\
\hline 1 & $:$ & \multicolumn{2}{|c|}{ Contact surface with SUS and heat exchange fluid } \\
\hline$Q$ & : & Averaged volumetric power density & {$[\mathrm{W} / \mathrm{L}]$} \\
\hline$t$ & $:$ & Elapsed time & {$[\mathrm{s}]$} \\
\hline$C_{p}$ & : & Heat capacity & {$[\mathrm{J} / \mathrm{kg} / \mathrm{K}]$} \\
\hline$\rho$ & : & Density & {$\left[\mathrm{kg} / \mathrm{m}^{3}\right]$} \\
\hline$\Delta T$ & : & Temperature difference & {$[\mathrm{K}]$} \\
\hline$T$ & : & Temperature & {$[\mathrm{K}]$} \\
\hline$F$ & $:$ & Fluid flow rate & {$\left[\mathrm{m}^{3} / \mathrm{s}\right]$} \\
\hline$V$ & $:$ & Volume & {$\left[\mathrm{m}^{3}\right]$} \\
\hline$X$ & $:$ & Conversion ratio & {$[-]$} \\
\hline$\Delta H$ & $:$ & Amount of heat & {$[\mathrm{kJ} / \mathrm{mol}]$} \\
\hline$P$ & $:$ & Pressure & {$[\mathrm{kPa}]$} \\
\hline$\rho_{M}$ & $:$ & Mol/volume & {$\left[\mathrm{mol} / \mathrm{m}^{3}\right]$} \\
\hline$\varepsilon$ & $:$ & Porosity & {$[-]$} \\
\hline$C_{p, M}$ & $:$ & Heat capacity per mol & {$[\mathrm{J} / \mathrm{mol} / \mathrm{K}]$} \\
\hline$\lambda$ & $:$ & Thermal conductivity & {$[\mathrm{W} / \mathrm{m} / \mathrm{K}]$} \\
\hline$k$ & $:$ & Reaction rate coefficient & {$[1 / \mathrm{s}]$} \\
\hline $1 / h$ & $:$ & Contact thermal resistance & {$\left[\mathrm{K} \cdot \mathrm{m}^{2} / \mathrm{W}\right]$} \\
\hline$u$ & : & Flow velocity & {$[\mathrm{m} / \mathrm{s}]$} \\
\hline
\end{tabular}

